\title{
An evaluation of the bond strength of multiple resin bolt and capsule combinations through laboratory testing and applied methodologies
}

\author{
I.R. Bierman' ${ }^{1}$, L. Gardner ${ }^{2}$, and P. Piper ${ }^{1}$ \\ ${ }^{1}$ Groundwork Consulting (Pty) Ltd, South Africa \\ 2Impala Platinum Ltd, South Africa
}

\begin{abstract}
This paper describes the implementation of a methodology and test results to determine the performance capability of a combination of $\varnothing 20 \mathrm{~mm}$ steel tendon resin bolts from ten separate suppliers, and $\varnothing 32 \mathrm{~mm}$ resin capsules from four separate suppliers. The methodology chiefly describes the parameter of the selected hole diameter which was $\varnothing$ $38 \mathrm{~mm}$. Installing $\varnothing 20 \mathrm{~mm}$ resin bolts inside $\varnothing 38 \mathrm{~mm}$ holes results in an excessive annulus, which significantly reduces the bond strength of the installation. By conducting a programme of laboratory pull testing by combining each resin bolt and resin capsule installed inside steel tubes with $\varnothing 38 \mathrm{~mm}$ internal diameter, the best combinations could be determined. The pull tests were supplemented by conducting similar installations inside Perspex tubes to provide visual observation of the installation process. In the laboratory, the test results showed that modified resin bolts provided the greatest resistance to pulling load with the least displacement. The modifications increased diameter of the penetrating end of the bolt, either by the addition of deformities to the steel, or by incorporating a helix into the design of the bolt profile. The work done addressed the need by Impala Platinum Limited (Impala Platinum) for effective resin bolt installations in large diameter holes.
\end{abstract}

\section{INTRODUCTION}

In late 2017, Impala Platinum commenced an investigation into alternative tendon support systems to replace the then hydraulically pre-stressed tendons. Resin bolting was identified as the most logical alternative. Ten potential resin bolt suppliers and four resin capsule suppliers were identified .

A large-scale evaluation was commissioned by Impala Platinum to determine the performance of each of the 40 possible bolt and resin combinations, as well as inspecting the manufacturing facilities of each potential supplier. The evaluation would be largely laboratory based and the top-performing combinations would be shortlisted; thereafter, the shortlisted bolts and resin products would be tested underground. A crucial aspect of the product evaluation was to conduct short encapsulation pull testing (SEPT) in the laboratory on samples installed inside tubes of $\varnothing 38 \mathrm{~mm} \mathrm{ID}$, as hole diameter measurements recorded underground by Impala Platinum indicated that using hand-held jackhammers and $\varnothing 34 \mathrm{~mm}$ drill bits, $\varnothing 38 \mathrm{~mm}$ holes are possible.

Impala Platinum's objectives for a support system was its suitability over a large range of depths across all shafts. The design criteria for displacement was simply to limit it to the minimum; this would mitigate against displacement in shallower workings and the potential for failure on geological structure boundaries, while allowing for some displacement on the deeper sections where a degree of stress-related host rock fracturing can be expected. 
In terms of load, the requirement was for a minimum of $100 \mathrm{kN}$. Importantly, the absolute level and variability of displacement at this load was the key evaluation criteria.

\section{Literature review}

While coal mines have been leading the implementation of support technologies, most notably resin bolting, platinum and chrome mines have made significant progress towards adopting newer support technologies. However, resin bolting is still not a common form of support in hard rock mines, Ferreira (2012). The challenges facing hard rock mines to implement a resin bolting support system are listed below, Snyman et al (2011) :

- Higher rock densities in hard rock mines versus coal

- Hole diameters are larger than in coal (typically greater than $30 \mathrm{~mm}$ versus smaller than $27 \mathrm{~mm}$ respectively) as the same drilling equipment and bits are used to drill blast and support holes, resulting in larger support holes

- Roofbolters, as used on coal mines, can exert upwards of $15 \mathrm{kN}$ of thrust, up to $250 \mathrm{Nm}$ of torque and spin at greater than $250 \mathrm{rpm}$, whereas hand-held rotary percussion drills as used on hard rock fall well short of this (less than $3 \mathrm{kN}, 80 \mathrm{Nm}$ and $200 \mathrm{rpm}$ )

- Rock temperatures are considerably higher in hard rock mines as compared to coal resulting in faster setting times.

In spite of these challenges, this type of support system has been finding favour in platinum mining, which has been going deeper and faces new geotechnical environments. Most notable is the change of the rock mass response from being controlled by geology to being driven by the stress environment. Gardner et al (2013) and Zindi (2008) of Impala Platinum, faced such a challenge with fourth-generation shafts situated in the intermediate depth range $(1000 \mathrm{~m}$ to $2250 \mathrm{~m})$. The issue was identified after an investigative approach to implementation that found the best option for a support system for the deep, fractured and corrosive environment, was a combination of resin bolting and fibrecrete.

The issue of annulus, the difference between the bolt and hole diameters, remains an important one for resin bolting. Ulrich et al (1989) found that for a 3/4 inch (approximately $19 \mathrm{~mm}$ ) diameter roof bolt installed in competent rock, the ideal annulus is $1 / 4$ inch (approximately $6.4 \mathrm{~mm}$ ). This implies a 1-inch $(25.4 \mathrm{~mm})$ diameter hole. As the annulus increases from the ideal, the quality of the resin mix and associated axial strength of the installation will decrease. It was also suggested that a pull test is not the most effective manner of determining the extent of resin mixing if the resin bonded length is greater than the load transfer length. In these instances, visual examination, albeit a subjective approach, is better. Bharti et al (2014), also suggest that the annulus should not be greater than $6 \mathrm{~mm}$, and made reference to Figure 1 (after Hagan), to illustrate the point. Figure 1 suggests that $3 \mathrm{~mm}-4 \mathrm{~mm}$ is the ideal range for resin annulus. 


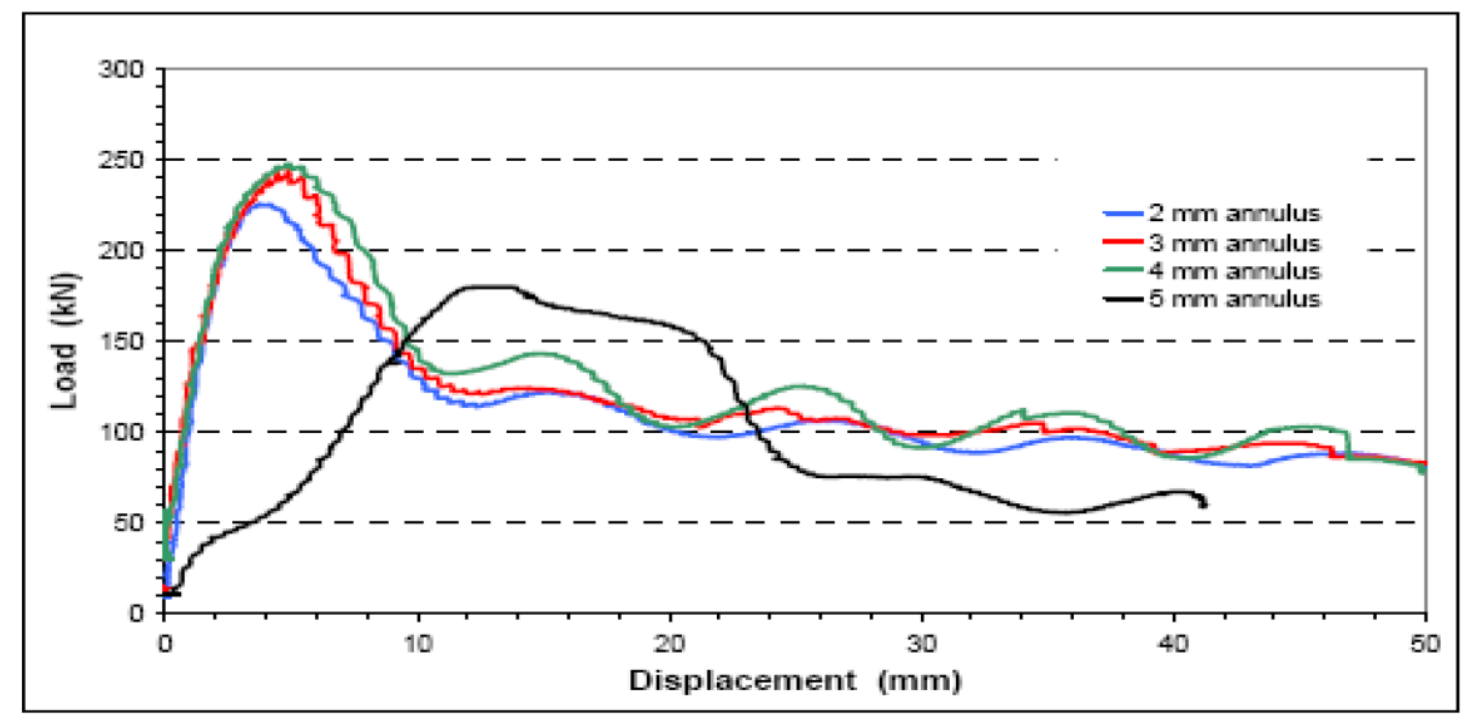

Figure 1. The effect of annulus on the load-bearing capability of a resin bolt (after Hagan)

Snyman et al (2011), describe how one prominent resin supplier conducted a programme of research and development with a goal of enabling resin bolting to be implemented successfully on hard rock mines. The key differences of hard rock mines as described above, were addressed through changes in the resin chemical formulation, capsule theology, and providing for the application of spin-to-stall by combining it with two-speed capsule technology where both slow and fast setting resins reside in a single capsule.

Ferreira (2012), further describes how the same supplier has developed a resin bolt designed to overcome the challenge of effective mixing of the resin where the hole diameter is large compared to the bolt diameter. This was achieved by adding paddles to the bolt profile, and extensive testing conducted with $20 \mathrm{~mm}$ diameter bolts and an average of $35 \mathrm{~mm}$ diameter holes (resulting in an annulus of $7.5 \mathrm{~mm}$ ), has demonstrated the ability of the paddles to shred the film of the capsule and provide consistent and effective mixing in an annulus well above the ideal range.

Canbulat et al (2005) state that the reinforcement of fully-bonded rock bolting support systems is a function of the strength and stiffness of the bond between the bolt and the rock. In the case of resin bolts, Campbell et al (2004) assert that this bond is provided by the resin mix as, in a fully resin-bonded rock bolt, the load transfer to the bolt is dependent on the shear stress capable of being generated on the interfaces of the rock and resin and the bolt and resin through mechanical interlocking. Campbell et al (2004) make reference to Figure 2 (after Fabjanczyk and Tarrant), to illustrate this mechanism. 


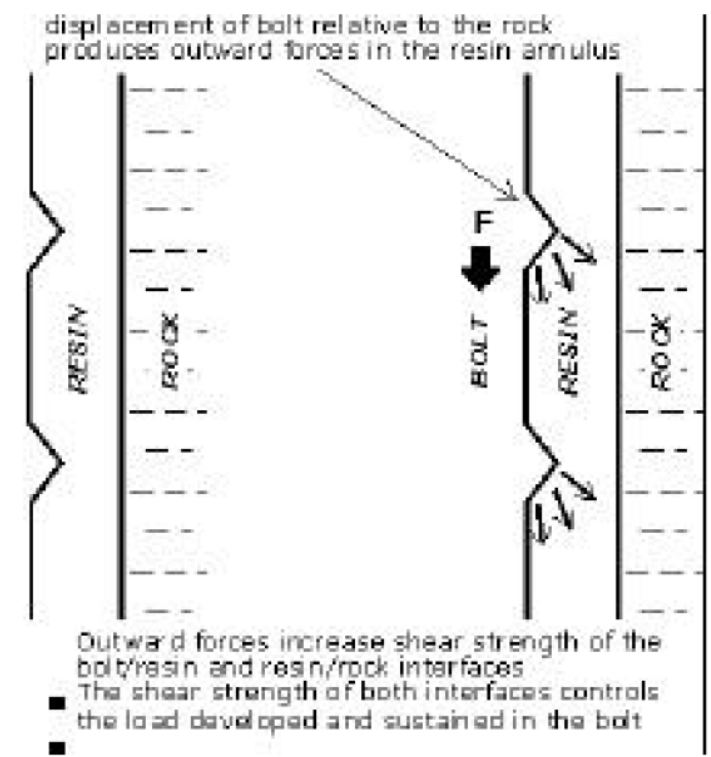

Figure 2. Mechanism of load transfer between a resin-bonded bolt and rock (after Fabjanczyk and Tarrant)

Canbulat et al (2005), maintain that the properties of strength and stiffness of the resin bond between bolt and rock can be tested in the laboratory or underground through short encapsulation pull testing (SEPT). A typical underground SEPT set-up is shown in Figure 3.

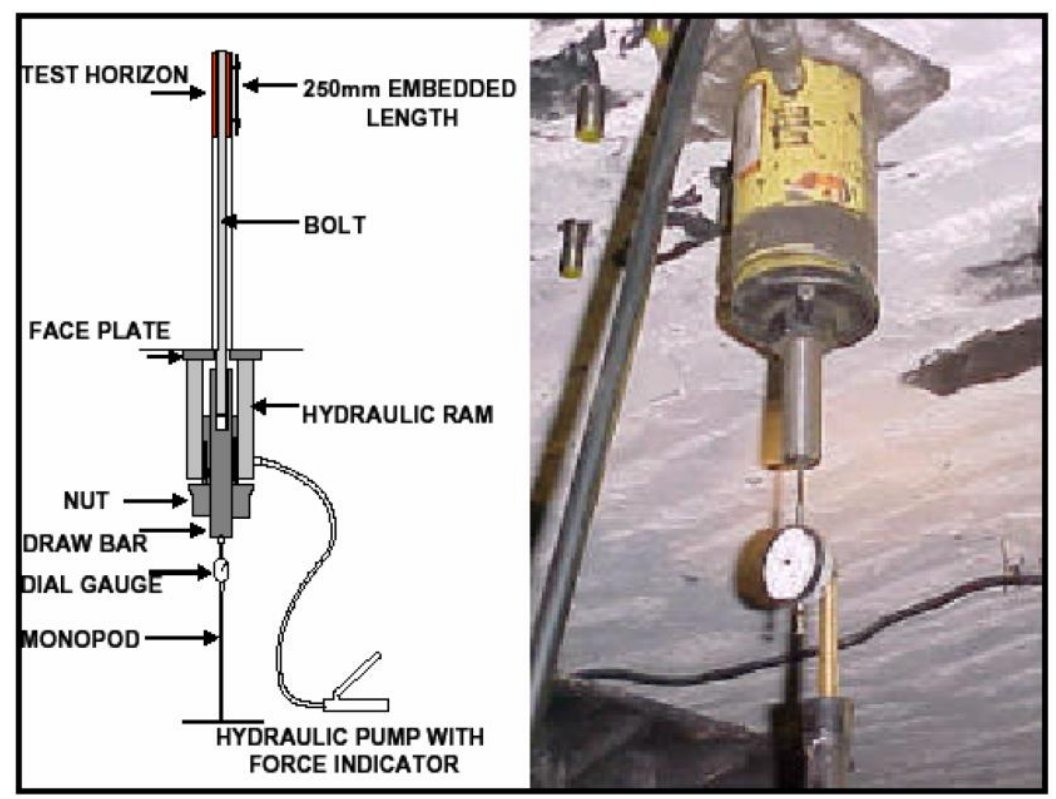

Figure 3 - Underground SEPT arrangement using a drawbar (after Canbulat et al)

Since it is necessary to shear the bond on the bolt and resin or resin and rock interface to determine bond strength, the authors found that by conducting numerous tests, that a bond length (the length of the bolt bonded by resin) of $250 \mathrm{~mm}$ is suitable for a $20 \mathrm{~mm}$ diameter bolt. SIM 020205 sets out guidelines for the SEPT methodology as follows: 
- Resin capsule length:

Capsule length $=\frac{(\text { Hole } \emptyset)^{2} m m-(B o l t \emptyset)^{2} m m}{(\text { Resin Capsule } \emptyset)^{2} m m} x$ Bond length $(\mathrm{mm})$

- Bond displacement is calculated by determining and negating extension of the bolt and drawbar

- Bond strength is to be calculated with the applied force at which the slope of the forcedisplacement graph falls below $20 \mathrm{kN} / \mathrm{mm}$

- Bond strength can be expressed as shear strength or bond stress on the either the resin-bolt or resin-rock interface, depending on where shear failure has occurred, as follows Pile et al):

$\sigma_{\text {bond }}=\frac{F}{\pi \emptyset_{\text {bond }} L_{\text {bond }}}$

where $\quad \sigma_{\text {bond }}=$ shear stress at failure interface $(\mathrm{MPa})$

$\mathrm{F}=$ load at failure $(\mathrm{N})$

$\varnothing_{\text {bond }}=$ diameter of failure interface $(\mathrm{mm})$

$\mathrm{L}_{\mathrm{bond}}=$ Bond length $(\mathrm{mm})$

- System stiffness is calculated from the load-displacement graphs of the SEPT and is typically measured between $40 \mathrm{kN}$ and $80 \mathrm{kN}$ :

$K=\frac{\Delta F}{\Delta d}$

where $\quad \mathrm{K}=$ system stiffness $(\mathrm{kN} / \mathrm{mm})$

$\Delta \mathrm{F}=$ change in load $(\mathrm{kN})$

$\Delta \mathrm{d}=$ change in displacement $(\mathrm{mm})$

\section{OVERVIEW OF THE PRODUCT SAMPLES AND TEST METHODOLOGY}

The profiles of the resin bolt samples provided by the suppliers for the test programme varied considerably. Two main categories of bolts were identified: unmodified and modified. The unmodified bolts were typically standard rebar-type resin bolts, as seen in Figure 1. The modified bolts all incorporated a unique design for increasing the cross-sectional dimension of the bolt over the end portion, either by deforming the steel in various ways, or adding elements to a basic rebar-type bolt. The intention of these modifications is to increase the diameter of the bolt over the modified section to decrease the annulus between the bolt and rock interface. This increases the bond strength of the installation over this length by providing improved mixing of the resin and catalyst up to the boundary of the hole diameter. However, this principle applies only over the section of the bolt that includes these modifications. Table I details the specifications of the resin and the material strength and modifications of the bolts. 
Table I. Resin bolt material strengths and modification characteristics and resin capsule shear strengths

\begin{tabular}{|c|c|c|c|c|}
\hline & \multicolumn{3}{|c|}{ Resin bolts } & \multirow{2}{*}{$\begin{array}{c}\text { Resin capsules } \\
\begin{array}{c}\text { Shear strength } \\
(\mathrm{MPa})\end{array}\end{array}$} \\
\hline & $\begin{array}{c}\text { Minimum } \\
\text { material strength } \\
(\mathrm{MPa})\end{array}$ & Modification & Bolt end type & \\
\hline Supplier 1 & - & $\begin{array}{l}\text { Helix added to } \\
\text { rebar bolt }\end{array}$ & $45^{\circ}$ tip & - \\
\hline Supplier 2 & - & $\begin{array}{c}\text { Bolt formed } \\
\text { into helix }\end{array}$ & Flat end $\left(90^{\circ}\right)$ & - \\
\hline Supplier 3 & 500 & $\begin{array}{l}\text { Bolt formed } \\
\text { into helix }\end{array}$ & Tri-lobe tip & 23 \\
\hline Supplier 4 & 500 & Paddles & Split end & $>23$ \\
\hline Supplier 5 & 500 & Paddles & $45^{\circ} \operatorname{tip}$ & \\
\hline Supplier 6 & - & Paddles & $45^{\circ}$ tip & \\
\hline Supplier 7 & - & Paddles & Split end & \\
\hline Supplier 8 & 520 & $\begin{array}{c}\text { Ribbed mining } \\
\text { rebar }\end{array}$ & Flat end $\left(90^{\circ}\right)$ & \\
\hline Supplier 9 & - & $\begin{array}{c}\text { Ribbed mining } \\
\text { rebar }\end{array}$ & $45^{\circ}$ tip & \\
\hline $\begin{array}{c}\text { Supplier } \\
10 \\
\end{array}$ & - & $\begin{array}{c}\text { Ribbed mining } \\
\text { rebar }\end{array}$ & $45^{\circ}$ tip & \\
\hline
\end{tabular}

In Table I, "- "indicates that this specification is not given in the supplier data sheet. However, in the case of the material strengths of the resin bolts, it is accepted that all suppliers' products are based on mining bar with a minimum yield strength of $500 \mathrm{MPa}$. The term paddles in Table 1 is used to describe all resin bolts where the modification is implemented through a deformation of the material through pinching or compression at selected points along the length.

Resin capsule supplier 3 provides resin in two strengths - standard and high shear strength. High shear strength $23 \mathrm{MPa}$ resin was provided for testing. Resin capsule supplier 4 provides one resin specification, with a nominal shear strength of $>23 \mathrm{MPa}$. Supplier literature from resin capsule suppliers 1 and 2, does not specify the shear strength of the resin supplied.

Among the modified bolts, three bolt products differed visually from the rest. These bolts all included a helix in the design of the bolt profile (See Figure 4), with the orientation of the helix such that with counter-clockwise spinning it would serve to move material to the end of the bolt at the extreme end of the hole.

Figure 4 shows the three main bolt types included in the test programme: an unmodified rebar bolt, a modified bolt and helix-modified bolts. It is evident that all three helix-modified bolts apply the helix concept in very different ways. From left to right in Figure 4: one adds a spring element to a basic rebar-type bolt, a second materially deforms the end of a rebar bolt by twisting it into a rough-form helix and a third has a square cross-section and is shaped into a helix along its entire length. Given their profiles, any improvement in bond strength offered by helix-modified resin bolts type one and two will apply only to the section of the bolt that is modified as the remaining length is the standard $20 \mathrm{~mm}$ rebar. The same applies to all the modified bolts, since these modifications are found only over a portion of the bolt.. The third helix-modified bolt, as it is in a helix form for its entire length, has the same bond strength throughout. 


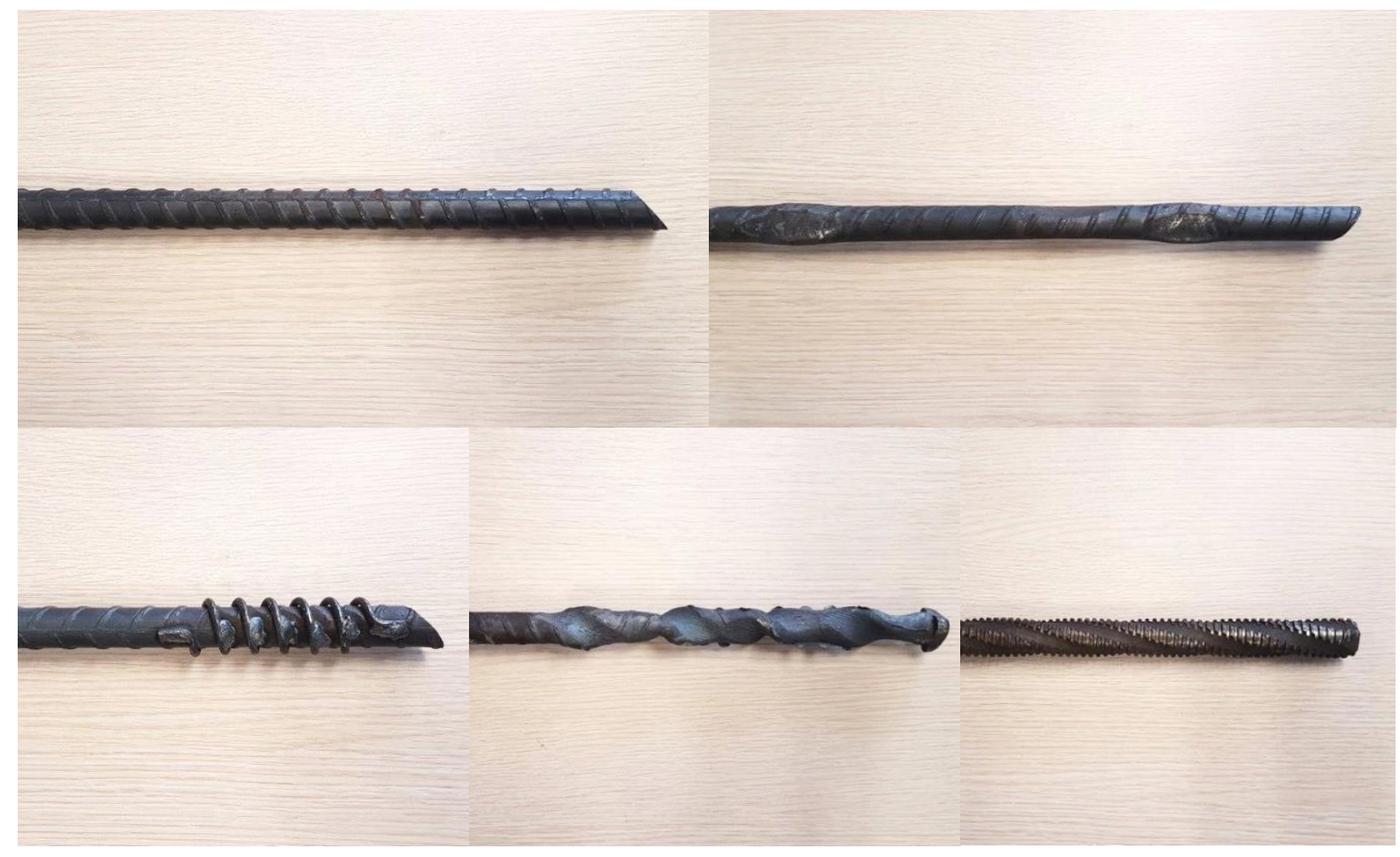

Figure 4. Three categories of bolts included in testing programme: unmodified (rebar) bolt (top left), modified bolt (top right) and helix-modified bolts (bottom)

The resin capsule samples provided all had similar specification: $32 \mathrm{~mm}$ diameter, 60 second resin, with a 15 second spinning time and 45 second hold time. The composition and ratios of resin mastic and catalyst are unique to each supplier. Figure 5 shows the resin capsule samples provided by each of the four suppliers.

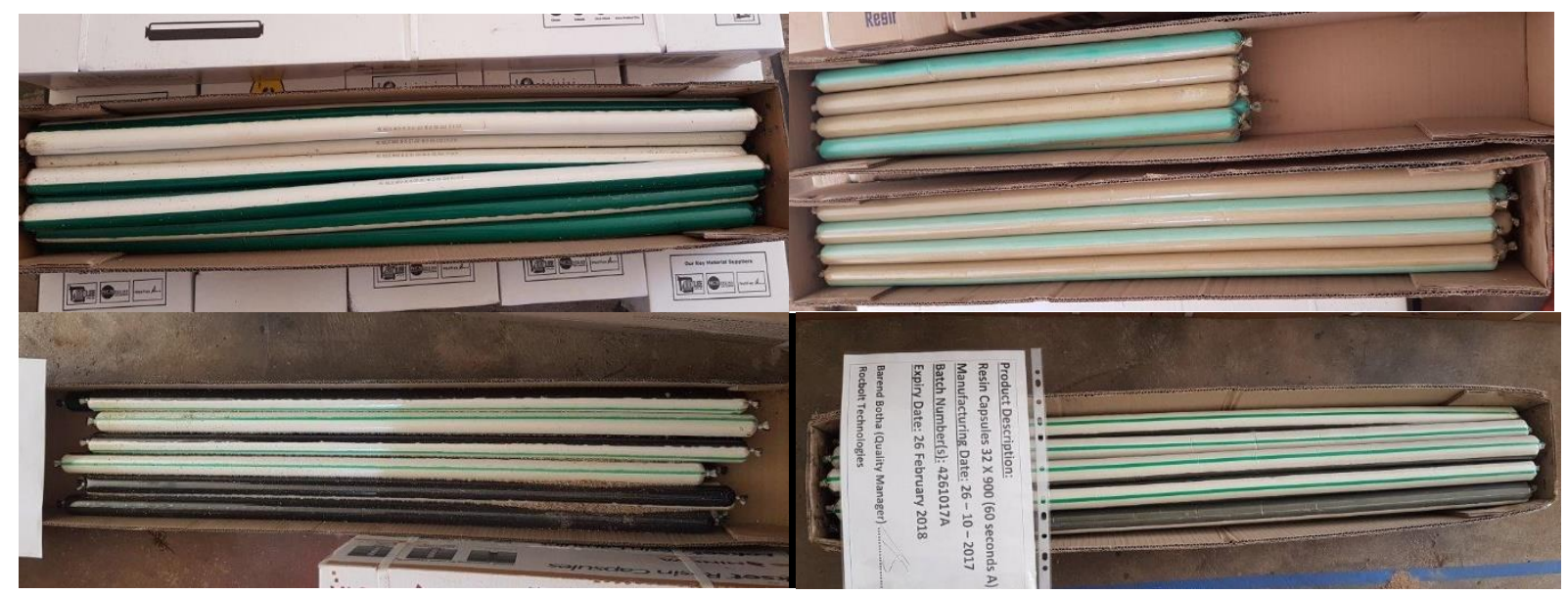

Figure 5. Photographs of resin capsules samples provided by four suppliers 


\section{SAMPLE PREPARATION AND TEST METHODOLOGY}

The laboratory test methodology employed for the test programme consisted of two main parts, physical tensile strength short encapsulation tensile (pull) testing, as well as visually-focussed Perspex testing.

SEPT samples were prepared using $300 \mathrm{~mm} \varnothing 51 \mathrm{~mm}$ outer diameter (OD) and $\varnothing 38 \mathrm{~mm}$ internal diameter (ID) steel tubes, with one end welded closed. The inner surface of the steel tubes was roughened by machining a fine $2 \mathrm{~mm}$ pitch, $0.5 \mathrm{~mm}$ deep thread over the entire length. The Perspex samples were prepared using two tube sizes of $1 \mathrm{~m}$ length: $\varnothing 36 \mathrm{~mm}$ ID with a $\varnothing 40 \mathrm{~mm}$ OD, and $\varnothing 40$ $\mathrm{mm}$ ID with a $\varnothing 50 \mathrm{~mm}$ OD. The $\varnothing 36 \mathrm{~mm}$ ID Perspex tube was selected as it was the standard size nearest to the $\varnothing 38 \mathrm{~mm}$ ID required. The smaller tube is inserted inside the larger tube for reinforcement against the high internal pressure generated during the spinning process such that the combined tube had a $\varnothing 36 \mathrm{~mm}$ ID and a $\varnothing 50 \mathrm{~mm}$ OD. The Perspex tubes had no internal roughening as the intention was only to observe resin mixing and not to conduct any physical testing.

Consistent sample preparation was key to eliminating variables related to the process of installation. To achieve this, all SEPT and Perspex samples were prepared on a spinning machine built specially for the purpose of resin bolting installations. Using the machine, the entire spinning process is automated, according to parameters entered by the operator. Table II shows the installation parameters entered for the SEPT and Perspex samples. It was intended to comply with the requirements of SANS 1534 as far as possible. Among other stipulations, steel tubes, resin capsules and bolt samples had to be conditioned to $21^{\circ} \mathrm{C} \pm 3{ }^{\circ} \mathrm{C}$ prior to installation. The length of resin capsules required was determined from a calculation of the volume required to fill between the bolt and tubes.

It was critical to meet the 15 second total spinning time requirement, as per the OEM specification, on the installation of the SEPT samples to ensure optimal mixing and bond strength. However, for the Perspex samples, as these were only intended for visual purposes, it was decided to maintain the same rate of insertion as the SEPT samples, which resulted in a longer spinning time due to the longer sample length.

Table II. Installation parameters for short encapsulation and Perspex samples

\begin{tabular}{|c|c|c|}
\hline Parameter & Short encapsulation & Perspex \\
\hline Spinning speed $(\mathrm{rpm})$ & 300 & 300 \\
\hline Spinning time during insertion $(\mathrm{s})$ & 7 & 15 \\
\hline Spinning time with bolt fully inserted $(\mathrm{s})$ & 8 & 8 \\
\hline Holding time $(\mathrm{s})$ & 45 & $20-23$ \\
\hline Temperature of samples at installation $\left({ }^{\circ} \mathrm{C}\right)$ & $18-24$ & 1000 \\
\hline Final bond length $(\mathrm{mm})$ & 250 & 36 \\
\hline Internal diameter $(\mathrm{mm})$ & 38 & 900 \\
\hline Capsule length $(\mathrm{mm})$ & 300 & 32 \\
\hline Capsule diameter $(\mathrm{mm})$ & 32 & \\
\hline
\end{tabular}


After installation of each SEPT sample, the closed-off end of each tube was cut to expose some part of the resin bolt within the set resin. A small portion of the open end of the steel tube was cut away, together with the closed end, the total length removed from the SE test sample was $50 \mathrm{~mm}$, leaving the required $250 \mathrm{~mm}$ bond length. SEPT samples were tested in a tensile testing machine, using a linear transducer to measure the displacement of the bolt within the resin from the exposed end when load is applied, as is appropriate to negate the extension of the steel bolt. An increasing load was applied to the test sample at a rate of between $50 \mathrm{kN} / \mathrm{min}$ and $60 \mathrm{kN} / \mathrm{min}$. The test was stopped prior to failure of the resin bolt or before the bolt pulled out of the resin, while the data acquisition system recorded displacement and load. The photographs (See Figure 6), show a SEPT sample before and after cutting (left, middle and top right) and installed in the tensile testing machine in preparation for a tensile load test (bottom right). The short encapsulation pull test arrangement replicated the underground SEPT arrangement as shown in Figure 3; but with significant improvement in accuracy of laboratory sample preparation and testing.

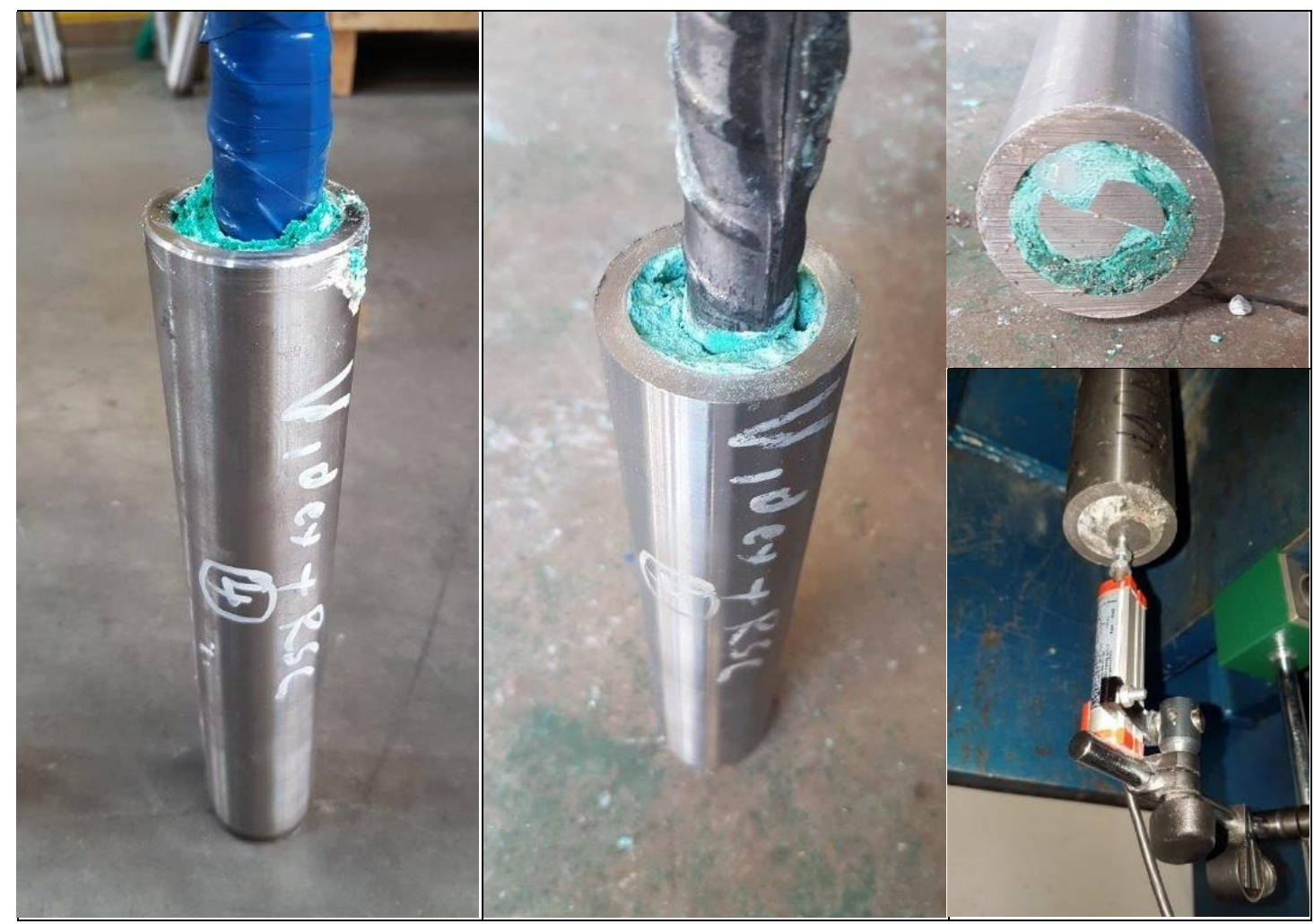

Figure 6. SEPT sample before (left) and after cutting (middle); bottom end of SEPT sample showing exposed cross-section of resin bolt (top right) and sensor attached to test frame contacting end of exposed resin bolt (bottom right)

This part of the laboratory testing phase involved the use of instrumented test equipment to test the tensile pull-out strength of the bolt and resin combination. Data obtained from each test batch could be analysed and condensed into a single figure that would enable determination of the relative performance of all combinations. The scoring system for the tensile tests on SEPT samples is given in Table III. The criteria of comparison includes: (1) the absolute mean peak load obtained by ten samples per combination; (2) the mean displacement at a load of $100 \mathrm{kN}$ of ten samples per combination; (3) the variability of the displacement at $100 \mathrm{kN}$ of ten samples tested per combination, in the form of two displacements from the mean. A score is assigned per criterion, using a linear relationship between the parameter value and the associated weighting, to give a total out of 100 . 
Table III. Scoring table for laboratory short encapsulation pull testing

\begin{tabular}{|l|c|c|c|}
\hline Categories & Parameter & Value & Weighting \\
\hline \multirow{2}{*}{ Maximum mean load at failure } & Min & $100 \mathrm{kN}$ & 0 \\
\cline { 2 - 4 } & Max & $200 \mathrm{kN}$ & 20 \\
\hline \multirow{2}{*}{ Mean displacement at $100 \mathrm{kN}$} & Min & $0 \mathrm{~mm}$ & 40 \\
\cline { 2 - 4 } & Max & $10 \mathrm{~mm}$ & 0 \\
\hline $\begin{array}{l}\text { Mean displacement }+2 \text { standard } \\
\text { deviations }\end{array}$ & Min & $0 \mathrm{~mm}$ & 10 \\
\cline { 2 - 4 } & Max & $40 \mathrm{~mm}$ & 0 \\
\hline
\end{tabular}

In relation to the Perspex (visual) testing, one sample per combination was prepared. The first aspect of the evaluation of these installations was to observe the effect of spinning each of the three types of bolts with each resin, and secondly to view a cross-section of the final installation per resin and bolt combination. After installation of the Perspex samples, the first $300 \mathrm{~mm}$ from the penetrating end of each resin bolt was sliced into $30 \mathrm{~mm}$ segments for inspection and analysis. This phase of testing was conducted for correlation with the SEPT results, in that it was expected that the best-performing combinations would also display the best resin mix homogeneity. The criteria of assessment were based on a visual interpretation of the physical properties of the segments per combination, which were as follows:

- Complete splitting of mylar film with no evidence of whole pieces within resin

- Mixing homogeneity

- Complete encapsulation of the bolt

- Centricity of the bolt within the tube.

\section{SHORT ENCAPSULATION PULL TEST RESULTS}

The results of the short encapsulation pull tests are detailed below for the three main categories of resin bolt; unmodified, modified and helix-modified. The mean graphs of a batch of ten tensile tests of each of the 40 combinations are displayed in Figure 7, where the three unmodified, four modified and three helix-modified bolt test mean graphs are identified by the same colour; green, blue and orange respectively. These are further enclosed within a shaded area of the same colour. This serves to illustrate the vast difference between unmodified and modified bolts, and then the further performance benefit realised from including a helix into the design of the bolt profile. It should be noted that one resin bolt classed as a helix-modified bolt has initial yield loads higher than the modified group of bolts but which eventually attenuate in load to the region occupied by the modified bolts. In this instance, it is the higher yield load which gives it the property of the helix-modified group of bolts. This bolt can be seen on the bottom right of Figure 4. The reason for the drop in load after yield is likely as a result of the lack of additional surface area created by the bolt profile to provide for the mechanism of load transfer as per Figure 2 as compared to the other two helix-modified bolts. 


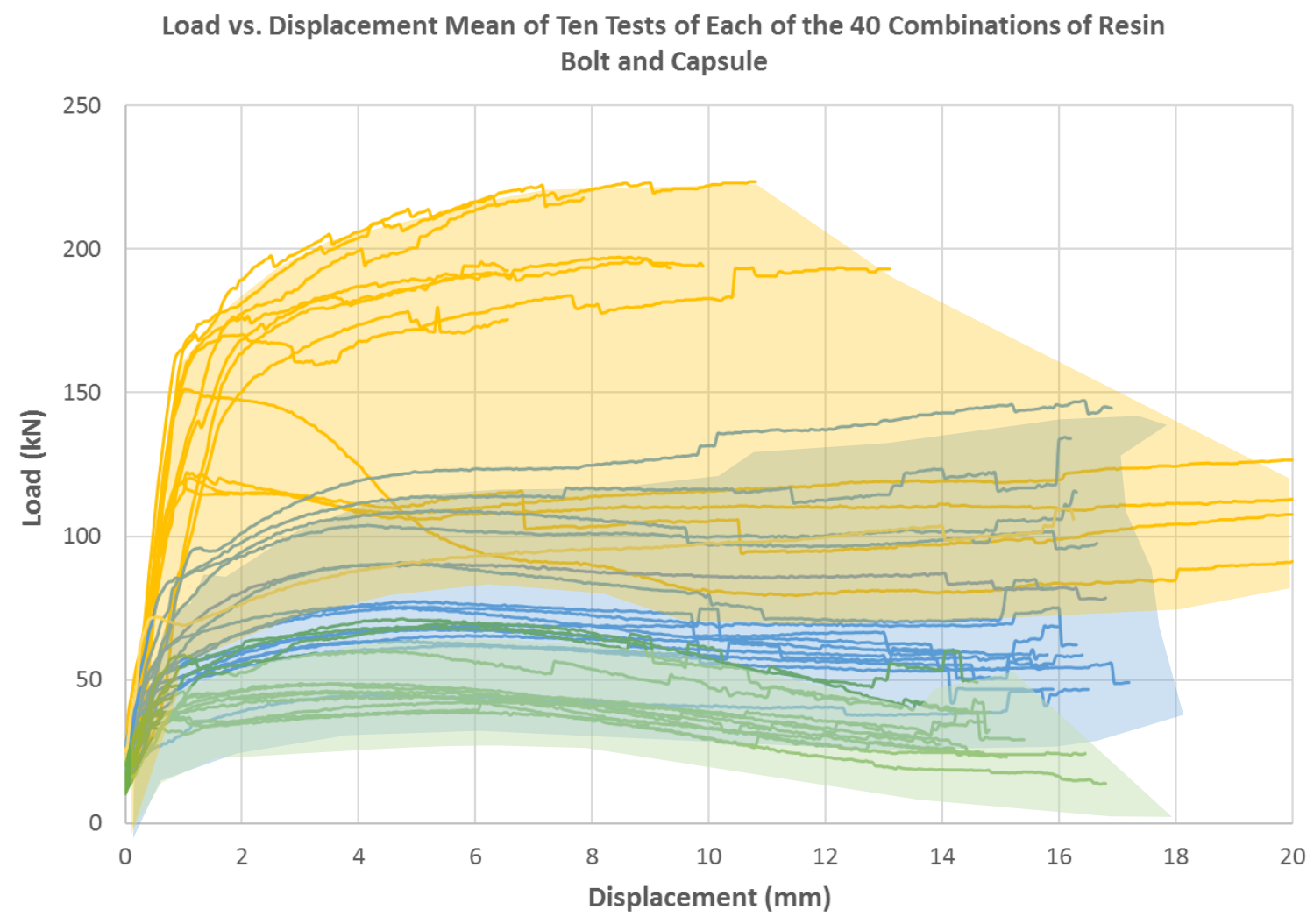

Figure 7. Mean of load vs. displacement of ten tests per combination of resin bolt and capsules with unmodified bolts shown in green, modified bolts in blue and helix-modified in yellow

In addition, using the scoring system shown (See Table III), a single score can be given to the batch of test results per resin bolt and capsule combination, as shown in Table IV. The values correlate with the regions of the graph of Figure 3, in that the modified bolts offer significantly better performance than unmodified bolts while helix-modified bolts return significantly better scores than all other bolts. The overlap or variability seen in the regions of the unmodified and modified bolts is due to the sensitivity of the modified and unmodified bolts to the resin it was combined with. The results of the combination of modified bolts with two of the four resin capsules were poorer than the other two, to the extent that they were similar to the best performing combinations of the unmodified bolts. This variability is also evident from the scores in Table IV, as well as the degree to which the helix-modified bolts are less sensitive to the different resin products. Finally, resins $A$ and $C$ returned better performance, on average, when paired with all resin bolts. Zero values in Table IV represent instances where the resin bolt and capsule combination failed to reach the minimum load parameter values to register a score.

Table IV. Scores for each resin and bolt combination

\begin{tabular}{|c|c|c|c|c|c|c|c|c|c|c|}
\cline { 2 - 12 } \multicolumn{1}{c|}{} & \multicolumn{3}{c|}{ Helix-modified } & \multicolumn{4}{c|}{ Modified } & \multicolumn{3}{c|}{ Unmodified } \\
\cline { 2 - 12 } \multicolumn{1}{c|}{} & Bolt 1 & Bolt 2 & Bolt 3 & Bolt 4 & Bolt 5 & Bolt 6 & Bolt 7 & Bolt 8 & Bolt 9 & Bolt 10 \\
\hline Resin A & 93.8 & 84.0 & 87.9 & 2.6 & 32.5 & 56.3 & 13.5 & 31.2 & 32.6 & 28.6 \\
\hline Resin B & 92.4 & 73.7 & 89.6 & 0 & 6.5 & 0 & 17.9 & 0 & 0 & 0 \\
\hline Resin C & 92.7 & 85.6 & 89.6 & 46.4 & 14.6 & 42.3 & 42.6 & 29.4 & 14.4 & 0 \\
\hline Resin D & 94.0 & 84.2 & 88.9 & 0 & 0 & 0 & 66.0 & 0 & 54.3 & 0 \\
\hline Average & $\mathbf{9 3 . 2}$ & $\mathbf{8 1 . 9}$ & $\mathbf{8 9 . 0}$ & $\mathbf{1 2 . 3}$ & $\mathbf{1 3 . 4}$ & $\mathbf{2 4 . 7}$ & $\mathbf{3 5 . 0}$ & $\mathbf{1 5 . 2}$ & $\mathbf{2 5 . 3}$ & $\mathbf{7 . 2}$ \\
\hline STDEV & 0.8 & 5.5 & 0.8 & 22.8 & 14.1 & 29.0 & 24.3 & 17.5 & 23.5 & 14.3 \\
\hline
\end{tabular}


Finally, as a standard measure of installation bond strength, the mean peak and yield loads generated by the combinations are used to calculate peak and yield shear strength as per equation [2].Additionally, pre-yield system stiffness is calculated as per equation [3]. As previously mentioned, the shear strength of the helix-modified and modified bolts is provided disproportionately by the section of the bolt that includes these modifications, except in the case of the third helix-modified bolt which is formed over its entire length. However, as it is expected that the unmodified $\varnothing 20 \mathrm{~mm}$ section of the helix-modified and modified bolts will have at least some shear strength, in all cases this was calculated over the total $250 \mathrm{~mm}$ bonded length of the SEPT samples to obtain an average shear strength. The bond diameter used for the shear strength calculations was taken as the nominal $20 \mathrm{~mm}$ diameter of the bolts as this was the failure interface, except in the case of helix-modified bolt 1 where the bond strength was calculated in two discrete parts, $20 \mathrm{~mm}$ diameter bolt and spring mean diameter, and summed. The shear strength calculations are shown in Table V and VI, followed by system stiffness calculations in Table VII. These calculation results can be seen to mirror the scoring calculations of Table IV as well as the division of performance shown in Figure 7. Coefficient of variation calculations show that the helixmodified bolts have the least variability between the four resin capsules, followed by the modified bolts, with unmodified bolts returning the highest variability.

Table V. Shear strength from mean peak load in $k P a$ per resin and bolt combination

\begin{tabular}{|c|c|c|c|c|c|c|c|c|c|c|}
\cline { 2 - 12 } \multicolumn{1}{c|}{} & \multicolumn{3}{c|}{ Helix-modified } & \multicolumn{4}{c|}{ Modified } & \multicolumn{3}{c|}{ Unmodified } \\
\cline { 2 - 12 } \multicolumn{1}{c|}{} & Bolt 1 & Bolt 2 & Bolt 3 & Bolt 4 & Bolt 5 & Bolt 6 & Bolt 7 & Bolt 8 & Bolt 9 & Bolt 10 \\
\hline Resin A & 13547 & 7485 & 12147 & 6239 & 4975 & 5415 & 7062 & 3715 & 3588 & 2905 \\
\hline Resin B & 12153 & 7310 & 12344 & 4711 & 3813 & 4460 & 6879 & 2303 & 2187 & 1237 \\
\hline Resin C & 14540 & 7685 & 12299 & 7364 & 5267 & 5377 & 9136 & 4192 & 4139 & 2706 \\
\hline Resin D & 14152 & 7380 & 12541 & 4526 & 4397 & 3220 & 7816 & 2927 & 3236 & 1626 \\
\hline Average & 13598 & 7465 & 12333 & 5710 & 4613 & 4618 & 7723 & 3284 & 3288 & 2119 \\
\hline STDEV & 1046 & 163 & 163 & 1343 & 645 & 1032 & 1026 & 837 & 822 & 813 \\
\hline
\end{tabular}

Table VI. Shear strength from mean yield load in $\mathrm{kPa}$ per resin and bolt combination

\begin{tabular}{|c|c|c|c|c|c|c|c|c|c|c|}
\cline { 2 - 12 } \multicolumn{1}{c|}{} & \multicolumn{3}{c|}{ Helix-modified } & \multicolumn{4}{c|}{ Modified } & \multicolumn{3}{c|}{ Unmodified } \\
\cline { 2 - 12 } \multicolumn{1}{c|}{} & Bolt 1 & Bolt 2 & Bolt 3 & Bolt 4 & Bolt 5 & Bolt 6 & Bolt 7 & Bolt 8 & Bolt 9 & Bolt 10 \\
\hline Resin A & 9792 & 6160 & 8690 & 3635 & 3852 & 2699 & 5195 & 3279 & 2559 & 1732 \\
\hline Resin B & 9098 & 6575 & 9880 & 3176 & 2884 & 3374 & 4533 & 1872 & 1732 & 866 \\
\hline Resin C & 10244 & 7570 & 9772 & 4414 & 3259 & 3266 & 6137 & 1783 & 2967 & 1630 \\
\hline Resin D & 10099 & 6090 & 10377 & 3476 & 2496 & 1974 & 5379 & 2082 & 2196 & 1184 \\
\hline Average & 9808 & 6599 & 9680 & 3675 & 3123 & 2828 & 5311 & 2254 & 2363 & 1353 \\
\hline STDEV & 510 & 682 & 711 & 528 & 577 & 642 & 660 & 695 & 526 & 402 \\
\hline
\end{tabular}


Table VII. System stiffness from mean yield load in $\mathrm{kN} / \mathrm{mm}$ per resin and bolt combination

\begin{tabular}{|c|c|c|c|c|c|c|c|c|c|c|}
\cline { 2 - 12 } \multicolumn{1}{c|}{} & \multicolumn{3}{c|}{ Helix-modified } & \multicolumn{4}{c|}{ Modified } & \multicolumn{3}{c|}{ Unmodified } \\
\cline { 2 - 12 } \multicolumn{1}{c|}{} & Bolt 1 & Bolt 2 & Bolt 3 & Bolt 4 & Bolt 5 & Bolt 6 & Bolt 7 & Bolt 8 & Bolt 9 & Bolt 10 \\
\hline Resin A & 175 & 159 & 112 & 134 & 123 & 102 & 130 & 94 & 66 & 57 \\
\hline Resin B & 177 & 156 & 155 & 116 & 70 & 117 & 159 & 56 & 40 & 24 \\
\hline Resin C & 213 & 172 & 191 & 101 & 91 & 91 & 101 & 67 & 57 & 55 \\
\hline Resin D & 190 & 167 & 120 & 84 & 89 & 56 & 136 & 65 & 64 & 40 \\
\hline Average & 189 & 163 & 145 & 109 & 93 & 91 & 132 & 70 & 57 & 44 \\
\hline STDEV & 17 & 7 & 36 & 22 & 22 & 26 & 24 & 16 & 12 & 15 \\
\hline
\end{tabular}

\section{VISUAL PERSPEX TEST RESULTS}

While the laboratory test results are conclusive in highlighting the performance benefits of adding modifications to the standard rebar resin bolt, it was a requirement from the outset that this improvement could be observed in practice. Observing the modified and, particularly, the helixmodified resin bolts during the installation process, gave clear indication that these elements increase the agitation of the resin mastic and catalyst mix up to the boundary of the tube diameter.

Cutting the Perspex samples into $30 \mathrm{~mm}$ segments displayed a variety of results from the installation process across all combinations. Examples of specific observations from these installations are shown in Figure 8.

The image at the top left of Figure 8 is typical of the overall condition of the $30 \mathrm{~mm}$ segments cut from installations on the three helix-modified bolts, and rated highly on the three criteria listed in Section 4. The images on the top middle and right are typical of installations on the four modified bolts, while the images on the bottom left and right are of those of unmodified bolts. The images may not be taken from the same segment number in all cases as it was intended to illustrate the typical condition per bolt type. 

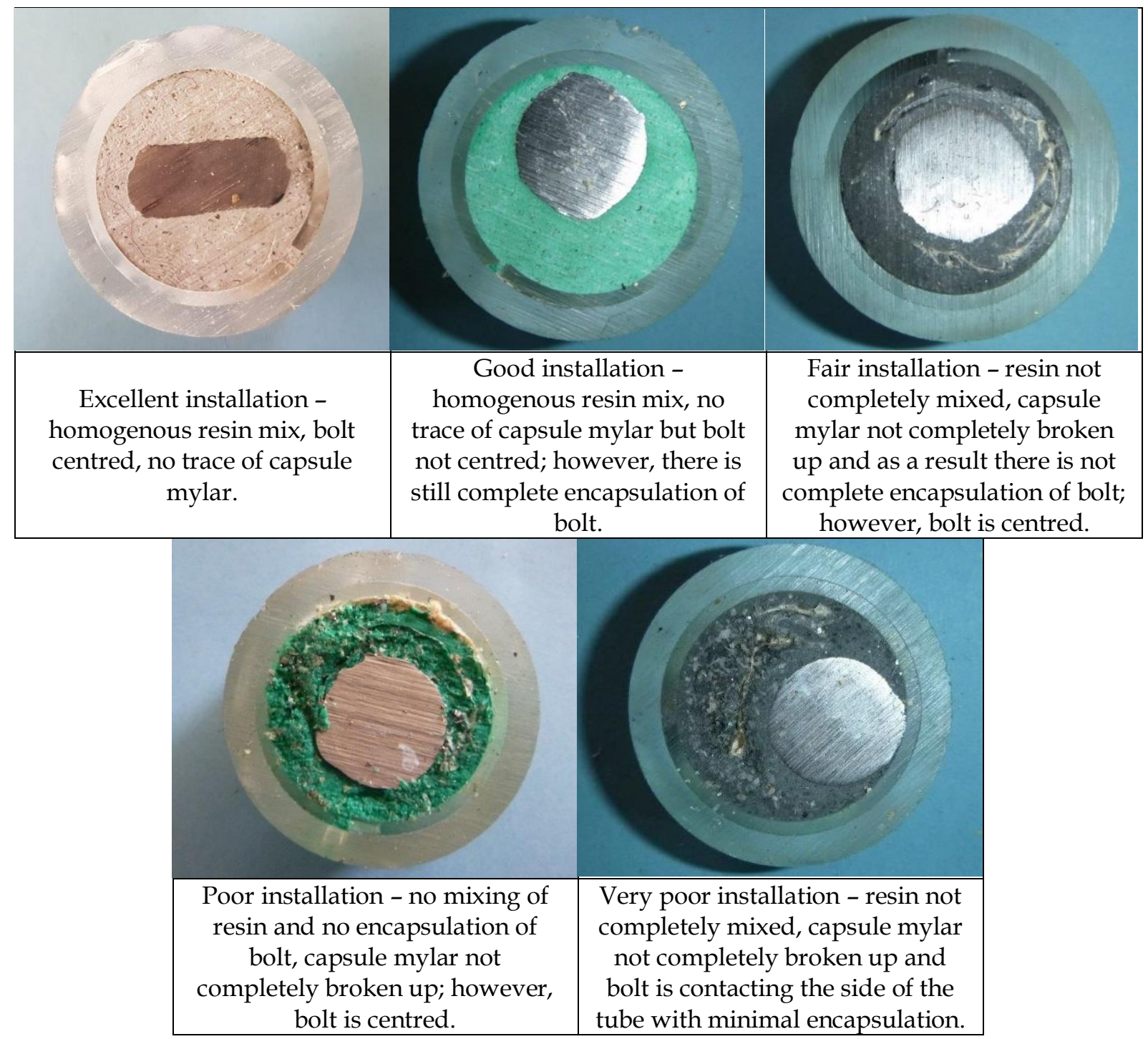

Figure 8. Examples of specific observations with Perspex installation slices

\section{CONCLUSIONS}

Visual and physical testing highlighted the inadequacy of a standard $20 \mathrm{~mm}$ resin bolt for use in holes of $38 \mathrm{~mm}$ in diameter. For this application, bolts must be modified to (1) include a section at the penetrating end of the bolt where the diameter is increased, either by addition of implements or deformities of the steel, so that these modifications serve as an agitator of the resin, and (2) incorporate a helix into the design that conveys the resin and catalyst mix to the end of the bolt that has greater surface area for resistance to pulling forces. The difference in bond strength between modified and unmodified bolts was significant: modified bolts, including helix-modified bolts, offer on average $195 \%$ and $176 \%$ greater bond strength than unmodified bolts in terms of peak and yield load respectively. Within the group of modified bolts, those that incorporated a helix design returned the highest bond strength: an increase of $133 \%$ and $96 \%$ on peak and yield load over the other standard modified bolts. Also, helix-modified bolts were less sensitive to the composition of the four resins, although two resin products did return better performance on average when paired with all bolt types. 
The test methodologies were designed to evaluate the specific resin bolt and capsule products identified by Impala Platinum for use in large diameter holes. However, it is recognised that the modified group of resin bolts, specifically the helix-modified group of bolts, significantly improve their bond strength in this application, albeit only at the penetrating end. Importantly, it emphasizes the need to understand the performance of the available tendon support systems within the context of choosing the one appropriate for the prevailing rock conditions.

\section{ACKNOWLEDGEMENTS}

The authors would like to thank Impala Platinum Limited for commissioning this work.

\section{REFERENCES}

Ferreira, P.H. (2012). A Perspective on Underground Support Technologies in Southern African Platinum Mines to Reduce Safety Risks and Enhance Productivity. Proceedings of the Fifth International Platinum Conference, 'A Catalyst for Change'. The Southern African Institute of Mining and Metallurgy. Sun City, South Africa.

Gardner, L.J., Fox, M.H. and Conley, N.L. (2013). Selecting support for new mine development - a case study from Impala Platinum Ltd. Proceedings of the Seventh International Symposium on Ground Support in Mining and Underground Construction, Australian Centre for Geomechanics, Perth, pp. 411-420.

Zindi, L. (2008). No. 17 Shaft Project-Overcoming 'Fourth Generation' Technical Challenges. Proceedings of the Third International Platinum Conference, 'Platinum in Transformation'. The Southern African Institute of Mining and Metallurgy. Sun City, South Africa.

Ulrich, B.F., Wuest, W.J. and Stateham, R.M. (1989). Relationships Between Annulus Thickness and the Integrity of Resin-Grouted Roof Bolts. Report of Investigations No. 9253. US Bureau of Mines Spokane Research Centre, Spokane, WA.

Bharti, S., Modi, J. and Kumar, R. (2014). Performance of Grouted Rock Bolts in Rock Mass. Proceedings of the National Seminar on Recent Trends in Mechanised Mining. Kothagudem, Telangana.

Snyman, W., Ferreira, P.H. and O'Connor, D. (2011). The New Generation Polyester Resin Capsule Support for Rock Bolt Solutions to the Mining Industry. Proceedings of the 6th Southern African Base Metals Conference. The Southern African Institute of Mining and Metallurgy. Phalaborwa, South Africa.

Canbulat, I., Wilkinson, A., Prohaska, G., Mnisi, M. and Singh, N. (2005). An Investigation into the Support Systems in South African Collieries. Report No. CR231/0205/SIM302. Safety in Mines Research Advisory Committee Project No. SIM 020205.

Pile, J., Bessinger, S., Mark, C. and Tadolini, S.C. (2003). Short Encapsulation Pull Tests for Roof Bolt Evaluation at an Operating Coal Mine. Proceedings of the 22nd International Conference on Ground Control in Mining. The National Institute for Occupational Safety and Health (NIOSH). West Virginia University, West Virginia, USA, pp. $226-232$.

Campbell, R., Mould, R. and MacGregor, S. (2004). Investigation into the Extent and Mechanisms of Gloving and Un-mixed Resin in Fully Encapsulated Roof Bolts. Coal 2004: Coal Operators' Conference, University of Wollongong \& the Australasian Institute of Mining and Metallurgy, pp. 203-214. 
South African Bureau of Standards. (2018). SANS 1534: 2018 (Edition 2.0). Resin Capsules for Use with Tendon Based Support Systems. South African Bureau of Standards...

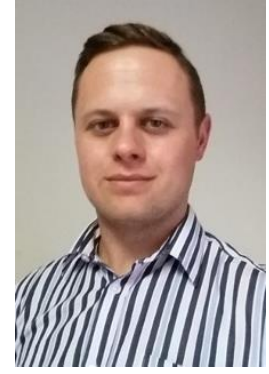

\section{Rohan Bierman}

Manager: Support Testing Services

Groundwork Consulting

After graduating in Mechanical Engineering from the University of Cape Town, Rohan joined Groundwork Consulting in 2011. Since then he has been involved primarily in mine support, conducting testing, evaluations and technical consulting for support suppliers of a variety of timberbased elongate and steel tendon products. He has also been involved in implementing a programme of support evaluations on collieries in the Mpumalanga Coalfields. Previous research done to review the de-rating factor applied to timber-based elongate support for use in shallow platinum mines has been presented to SANIRE Symposium. Rohan has also assisted in project management of some of Groundwork Consulting's typically sophisticated instrumentation monitoring programmes. 